\title{
INHALT SVERZEICHNIS.
}

Einleitung . . . . . . . . . . . . . . . . . . $7-8$

A. Zu Hessens Kritik an dem Brentanoschen Argument für das Kausalprinzip . . . . . . . . . . . . . . . . . . . 8-11

B. Zur Kritik der Wesensschau . . . . . . . . . . . . . . . . 11-58

I. Betrachtungen zur Tatsächlichkeit der Wesensschau und zu ihrer Verwendbarkeit als wissenschaftlichen Erkenntnisprinzips . . . . . . . . . . . . . . . . . . . . . . . 11- 40

1. Die Tatsächlichkeit der Wesensschau . . . . . . . . 11-27

a) Zergliederung einiger Notwendigkeitsurteile, die die Behauptung von der Existenz der Wesensschau nicht stützen . . . . . . . . . . . . . . . . 13-23

b) Bedenken gegen die Richtigkeit dieser Behauptung . 23-27

2. Die wissenschaftliche Verwendbarkeit der Wesensschau . 27-40

II. Eine in der wissenschaftlichen Methode verwendbare Sicherung von Notwendigkeitsurteilen, die man als Wesensschau bezeichnen könnte. . . . . . . . . . . . . . . . . . $40-44$

III. Auseinandersetzung mit Hessen:

1. hinsichtlich seiner Lehre von der objektiven Evidenz . 44-46

2. hinsichtlich der von ihm gegebenen Begründung der obersten Denkgesetze . . . . . . . . . . . . . . 46-50

3. hinsichtlich seiner Behauptung vom synthetischen Charakter dieser Gesetze . . . . . . . . . . . 50-58 
